\title{
Genetic parameters and alternatives for evaluation and ranking of Nellore young bulls in pasture performance tests ${ }^{1}$
}

\section{Breno de Oliveira Fragomeni ${ }^{2}$, Daiane Cristina Becker Scalez ${ }^{3}$, Fábio Luiz Buranelo Toral'2, José Aurélio Garcia Bergmann², Idalmo Garcia Pereira², Paula Souza Teixeira da Costa ${ }^{2}$}

\author{
${ }^{1}$ Funded by FAPEMIG (PPM-00456-11) and CNPq (502401/2009-5). \\ 2 Universidade Federal de Minas Gerais. \\ ${ }^{3}$ Universidade Federal de Mato Grosso.
}

\begin{abstract}
The objective of this study was to estimate (co)variance components for weight at 550 days, average daily gain and an index with both traits, and to compare alternatives for evaluation and ranking of Nellore young bulls in pasture performance tests. The heritability estimates were $0.73,0.31$ and 0.44 for weight at 550 days, average daily gain and index, respectively. Animals were ranked according to their predicted breeding values or the phenotypic deviations in relation to the mean of the test. Although the correlations between breeding values and phenotypic deviations were high, there were differences in the number of animals selected in common when the selection criteria were the predicted breeding values or the phenotypic deviations. Mixed models are more appropriate than the least squares method and should be utilized in the evaluation of young bulls in performance tests.
\end{abstract}

Key Words: breeding value, heritability, least square, mixed models, selection

\section{Introduction}

The Brazilian cattle herd consists of 176.6 million animals, of which $77.5 \%$ are considered to be beef cattle. About 56.1 million of these animals are females in reproductive age (AgraFNP, 2011). In the year 2010 nearly 7 million semen doses were commercialized in Brazil (ASBIA, 2010), which is enough to inseminate 4.4 million cows (1.6 doses/cow). In this manner 51.7 million beef cattle cows are mated in natural mating. Considering a bull: cow ratio of 1:35 and with a $25 \%$ annual bull replacement (Pereira, 2008), this means an annual demand of about 369 thousand young bulls.

One alternative to identify the breeding value and to rank the animals is the performance test, which is a common tool in Brazilian beef cattle breeding programs. This test is recommended when the selection criteria have high heritability (Razook et al., 1997). In this test, the animals are kept in controlled environmental conditions and the performance information is analyzed to rank the mating candidates according to an index (Razook et al., 1997). The index prevents the existence of two or more animals ranked at first when two or more traits are considered. This ranking might be performed by the least squares method, in which the data are adjusted for the fixed effects, and the differences between the individuals after this adjustment are used as indicators of differences in their breeding values. In this situation, records from previous performance tests and from relatives are not used in the evaluation of animals in the current test.

To make it possible to estimate the solutions for the fixed effects and to predict the random effects simultaneously, the mixed model methodology should be used (Henderson et al., 1959). In the mixed model context, the animal model can be an interesting option to evaluate the performance tests data, because it allows the incorporation of all the data from other tests and considers the relationship between the individuals, which increases the accuracy of the predicted breeding values.

Given that it is necessary to genetically identify a bigger amount of young bulls, decrease the generation interval and perform these evaluations with higher accuracy early, the objective of this study was to estimate genetic parameters for the weight adjusted at the age of 550 days, average daily gain during the performance test and an index, and to evaluate alternatives of analysis and ranking of performance data for Nellore young bulls in pasture performance tests.

\section{Material and Methods}

The data used in this study originated from 3,796 Nellore young bulls that were participants of 43 pasture performance tests carried out by the group Provados a Pasto. The 43 tests occurred between the years 1997 and 
2008 on commercial farms in the state of Goiás, Brazil. The animals began the tests with 214 to 320 days of age. Each test group was formed by animals from different farms with maximum age difference of 90 days. After the first weighing they were subjected to an adaptation period with average duration of 70 days. At the end of this period the initial weighing was performed, and the tests took 221 days (on average), with the animals maintained in a pasture regime with mineral supplementation only. The weights at the end of the test were standardized for 550 days of age (W550) by linear adjustments that considered the average daily gain in the test period.

The traits analyzed were weight adjusted at 550 days (W550); average daily gain during the test (ADG), obtained by dividing the weight gain during the test by the number of days on test; and an index (IND) obtained by pondering the standardized deviation of W550 and ADG by 0.4 and 0.6, respectively (Razook et al., 1997). The index was considered because it might be a suitable strategy to select bulls combining growth and weight traits (Baldi et al., 2012) in a situation where the evaluation for live weight and growth traits could result in a different classification. The deviations were calculated by the following equation:

$$
d_{h i j}=\frac{\text { observation }_{h i j}-\overline{\text { observation }_{h j}}}{\hat{\sigma}_{\text {observation }_{h j}}}
$$

where $d_{h i j}=$ standardized deviation of trait $h$ for animal $i$ in

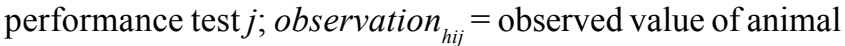
$i$ for trait $h$ in test $j$; $\overline{\text { observation }_{h j}}=$ average value of trait $h$ in test $j$; and $\hat{\sigma}_{\text {observation }}=$ standard deviation estimated for trait $h$ in test $j$.

The evaluations through the least squares method were performed for each test separately, including the covariable age at the end of the test as fixed effect, based on the following model:

$$
y_{h i j k}=u_{h j}+b_{h(j)}\left(a g e_{k}\right)+e_{h i j k}
$$

where $y_{h i j k}=$ observed value for animal $i$ in test $j$ at age $k$, for trait $h ; u_{h j}=$ estimated mean of test $j$ for trait $h ;$ age $_{k}=$ age of the animal at the end of the test; $b_{h(j)}=$ linear regression coefficient for the age nested inside test $j$ for trait $h$; and $e_{h j i k}=$ random error associated with each observation.

After the adjustment of the phenotypic values for the age effect, the standardized value of each animal contained the additive direct genetic value and a random error. These values were used as selection criteria. Analysis and ranking of animals were performed on software $\mathrm{R}$ ( $\mathrm{R}$ project, version 2.14).

Animals were also ranked according to the BLUP (best linear unbiased predictor) of the breeding values, obtained through the mixed models. For this analysis the following statistic model was considered:

$$
y_{h i j k}=u_{h j}+P T_{h j}+b_{h(j)}\left(a g e_{k}\right)+a_{h i}+e_{h i j k}
$$

where $P T_{h j}=$ fixed effect of performance test $j$ for trait $h$; $a_{h i}=$ additive direct genetic effect of animal $i$ for trait $h$; the other terms have been previously described. This model can be described in matrix notation as:

$$
y=X b+Z a+e
$$

where $y=$ vector of observations; $X=$ incidence matrix associated with the fixed effects; $b=$ solution vector for the fixed effects of each performance test and the covariable age; $Z=$ incidence matrix associated with the random effects; $a=$ solution vector for the additive direct genetic effect for each animal; $e=$ random error vector. In this model the variance components were estimated using software REMLF90 under single-trait and two-trait animal models, considering all the possible combinations between the pairs of traits.

Afterwards, to attain the BLUP and the PEV (prediction error variance) of the breeding values, using software BLUF90, 43 files were formed with the data of the animals participating in the tests. In this way, file 1 was composed only of data of animals from test number 1; file 2 was formed by the data of the first and second tests, and so forth, so file number 43 was composed of all the tests. Thus, the mixed model equation (MME) for each test was solved only with the data available when that test was performed. The BLUP solutions for each test were obtained by solving the following mixed model equations:

$$
\left[\begin{array}{cc}
X^{\prime} X & X^{\prime} Z \\
Z^{\prime} X & Z^{\prime} Z+A^{-1} \alpha
\end{array}\right]\left[\begin{array}{l}
\hat{b} \\
\hat{a}
\end{array}\right]=\left[\begin{array}{c}
X^{\prime} y \\
Z^{\prime} y
\end{array}\right]
$$

where $A^{-1}=$ the inverse of the numerator relationship matrix; and $\alpha=$ ratio between the estimates of residual and additive direct genetic variances obtained in singletrait analysis.

To compose the relationship numerator matrix, a recursive algorithm was used to keep only the individuals with information and their ancestors on the database. All the individuals that did not have observations, were not parents of any animal with data, did not have at least one known ancestor or those related to only one animal on the database were excluded. This procedure was repeated until there were no more individuals with these definitions. Thus, the numerator relationship matrix was composed of 5,230 animals.

The accuracy for the predicted breeding values was calculated through the following equation, which estimates the correlation between the predicted and the real breeding value (BIF, 2010): 


$$
a c c_{h i j}=\sqrt{\frac{\hat{\sigma}_{a_{h}}^{2}-p \hat{e} v_{h i j}^{2}}{\hat{\sigma}_{a_{h}}^{2}}}
$$

where $a c c_{h i j}=$ accuracy for the predicted breeding value of animal $i$ in test $j$ for trait $h ; \hat{\sigma}_{a_{h}}^{2}=$ genetic additive variance of trait $h$; and $p \hat{e}_{h i j}=$ prediction error variance for animal $i$ in test $j$ for trait $h$.

Subsequently, Spearmans correlation between the residuals of the least squares method and the predicted breeding value obtained by the mixed model equations system for each test were calculated to compare the classification made with both methods. The animals were ranked according to the selection criteria of both models and, later, the percentage of animals selected in common in the two methods were calculated for the top $10 \%$ and top $20 \%$.

\section{Results and Discussion}

The means \pm standard deviation for W550 (Table 1) were between the $274.72 \pm 43.76 \mathrm{~kg}$ found by Boligon et al. (2010) and the $347.14 \pm 63.55 \mathrm{~kg}$ found by Yokoo et al. (2007) with the Nellore breed. The results of ADG were also close to those obtained by Pereira et al. (2009), $0.445 \pm 0.200 \mathrm{~kg} /$ day. Even though the studies cited were carried out with both males and females and did not work with performance tests, these values support the use of the database of this essay as representative of Nellore male cattle in Brazil.

Fluctuations were found in the average values in each test (Figure 1) due to changes in environmental conditions, except for IND, which was analyzed as a deviation of

Table 1 - Descriptive statistics of the traits weight at 550 days (W550), average daily gain (ADG), index and age at the end of the test (Age) for Nellore young bulls in pasture performance tests

\begin{tabular}{lcccccc}
\hline Trait & Number of observations & Mean & Standard deviation & Minimum & Maximum & Coefficient of variation (\%) \\
\hline W550 (kg) & 3,796 & 325.96 & 40.69 & 186.8 & 466.8 & 12.48 \\
ADG (kg/day) & 3,796 & 0.50 & 0.15 & -0.018 & 0.96 & 30.00 \\
Index & 3,796 & 100 & 13.11 & 40.48 & 153.39 & 13.11 \\
Age (days) & 3,796 & 559 & 30.74 & 452 & 666 & 0.05 \\
\hline
\end{tabular}
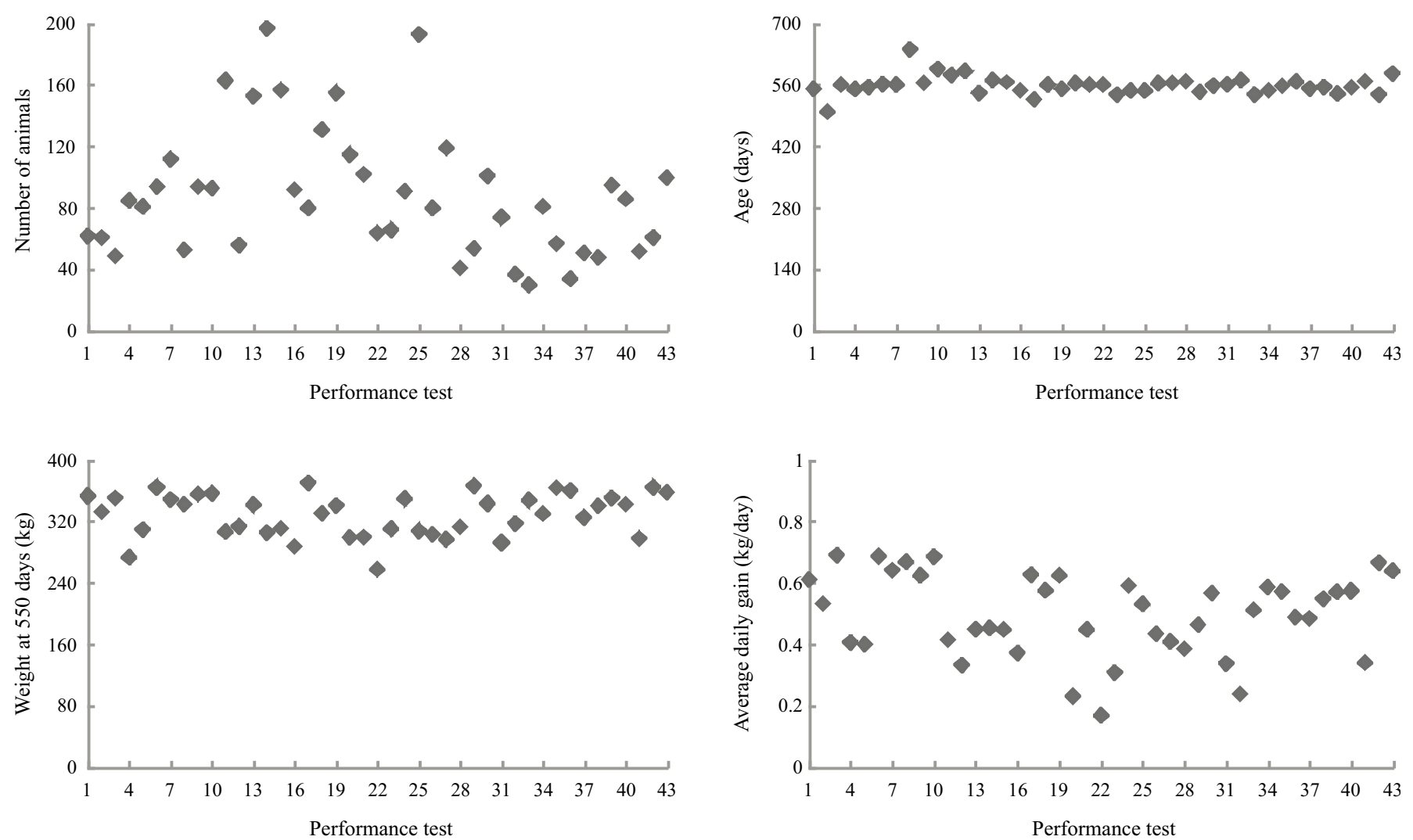

Figure 1 - Average values of number of animals, age, weight at 550 days and average daily gains of Nellore young bulls in each of the 43 pasture performance tests. 
each test and had its values standardized to 100 in each performance test. There were also fluctuations in the number of animals and in the average final age in each test.

The heritability estimates ranged from moderate to high in the single-trait analysis (Table 2). In the two-trait analysis the heritability estimates were lower than the single-trait, except for W550, in which no changes were observed. For ADG the values were 0.31 when analyzed with W550 and 0.33 when analyzed with IND. For the index, the values were estimated at 0.42 in the analysis with W550 and at 0.47 with ADG.

The heritability for weight at 550 days was higher than the 0.37 reported by Boligon et al. (2010) and lower than the 0.75 found by Gonçalves et al. (2011). Paneto et al. (2002) estimated heritability values of 0.23 for ADG, and this estimate was lower than those found in this study. The estimated heritability for the index tended to approach those estimated for ADG, which is in agreement with Azêvedo et al. (2005), who suggested that the heritability of the index tends to approach the values found for the trait of lowest heritability.

The differences found in heritability estimates compared with those reported in the literature can be explained in part by the strong environmental control that exists in a performance test. In this kind of test the animals are always held in controlled environmental conditions, which makes the genetic differences between them more explicit, encouraging the phenotypic selection.

Considering the heritability estimates for W550, ADG and index (single-trait analysis), the accuracy for those selection criteria based on the least squares method would be $0.85,0.56$ and 0.66 (square root of the heritability values), respectively, whereas the mean values for the mixed model method were $0.85,0.59$ and 0.69 (Figure 2), respectively. These accuracy values increased as information from new tests was included in the system of mixed model equations for traits ADG and IND $(\mathrm{P}<0.01)$. According to Tosh \& Wilton (1994), a higher number of genetic links in the numerator relationship matrix has an important effect on

Table 2 - Estimates of heritability (from single-trait analysis, in diagonal), genetic correlations (above diagonal) and phenotypic correlations (below diagonal), for weight at 550 days (W550), average daily gains (ADG) and index of Nellore young bulls in pasture performance tests

\begin{tabular}{lccc}
\hline & W550 & ADG & Index \\
\hline W550 & 0.73 & 0.74 & 0.84 \\
ADG & 0.69 & 0.31 & 0.93 \\
Index & 0.55 & 0.51 & 0.44 \\
\hline
\end{tabular}

the accuracy estimates, which explains the increase in these values. Because accuracy is measured as a function of the predicted error of variance and represents the estimated correlation between the predicted and real breeding values, by increase in its value, we can infer that the results achieved using the animal model approach the true breeding value as new information is included.

Spearman's correlation between the residual results of the least squares method and the predicted breeding values by the mixed models had mean values of $0.98,0.91$ and 0.94 for W550, ADG and index, respectively (Figure 2). These values showed a significant decrease as new data were added to the system of equations for ADG and IND $(\mathrm{P}<0.05)$. There were tests in which the correlation values were near 0.8 , which suggests some difference in the classification of animals. The implication of these differences was observed when the percentages of animals selected in common were calculated. The average values were $88 \%, 66 \%$ and $79 \%$ for W550, ADG and IND, respectively, when the top $10 \%$ animals were selected and $92 \%, 76 \%$ and $81 \%$ when the top $20 \%$ animals were selected, respectively (Figure 3 ). A significant decrease was observed in the percentage of animals selected in common with the addition of data to the system of mixed model equation only when the top $10 \%$ ranked animals were selected for the traits ADG and IND $(\mathrm{P}<0.01)$. Thereby the differences between the two methods could increase over time.

Because the accuracy values were higher in the mixed models for traits ADG and IND, it is possible to infer that the predicted breeding values obtained by this method are closer to the real values, when compared with those obtained by the least squares method. Thus, the use of the mixed models in performance tests would increase the benefits of that, giving estimates with results closer to the true breeding value. The increase in accuracy estimates when new data was added to each analysis confirms that this addition, along with the inclusion of the numerator relationship matrix, allows for better predictions through the mixed models for the traits ADG and IND, while for the trait W550 the same differences were not observed between the mixed models and the least squares method, probably because of the higher heritability estimates.

Since the selection for animals in performance tests is performed by the adjusted phenotypic values by the least squares method, those with higher breeding value for ADG and IND could be being discarded. In this way, the phenotypic selection that is performed in these tests should favor the selection of animals with higher breeding value for W550, without necessarily improving the other traits. This procedure may result in an increase in the weight at 

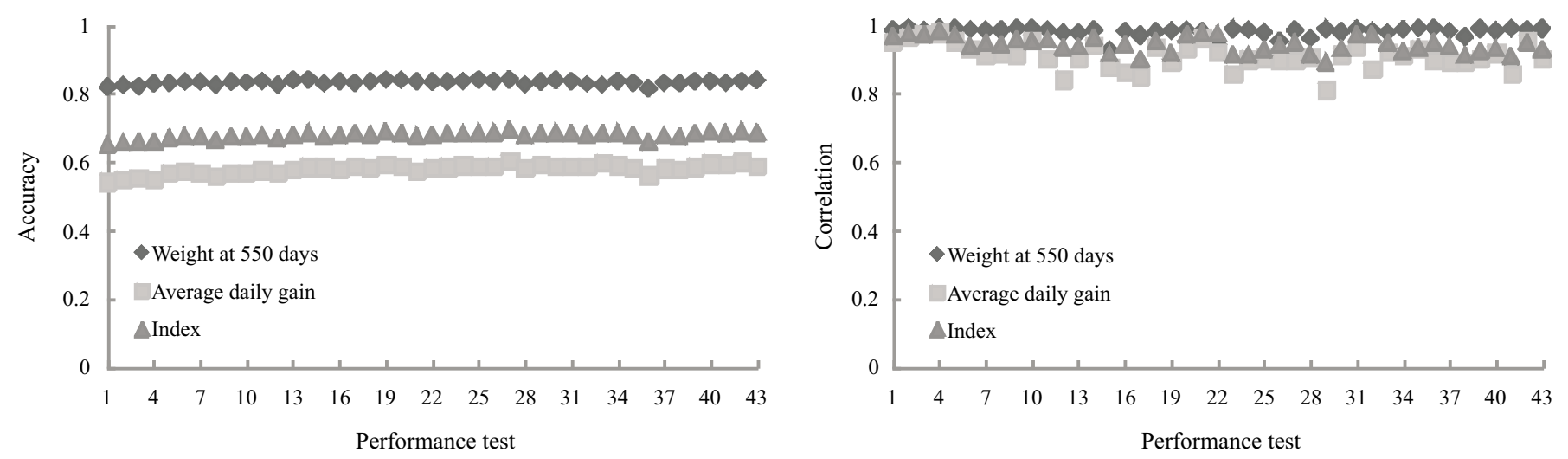

Figure 2 - Estimates of accuracy obtained in the mixed models and Spearman's correlations between the breeding values predicted by the mixed models and the phenotypic residuals of the least squares method in Nellore young bulls in pasture performance tests.
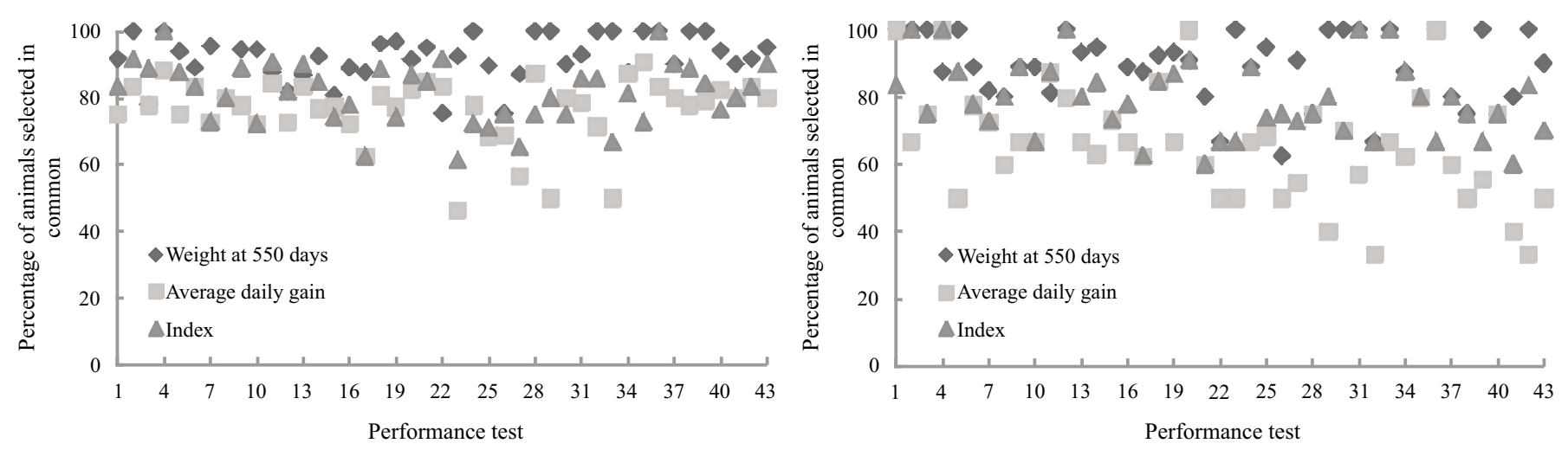

Figure 3 - Percentage of Nellore young bulls in pasture performance tests and selected in common according to predicted breeding values and phenotypic deviations with selection of the top $20 \%$ (left) and $10 \%$ (right) ranked animals.

the beginning of the test, instead of a weight gain during the performance test. In this case, an index made by a combination of the traits of interests can be a useful tool, because it allows the selection for body weight and average daily gain in one evaluation.

\section{Conclusions}

The genetic additive variance found for weight adjusted at 550 days of age, average daily gain and the index with both traits show that it is possible to improve the genetic values in these traits by selection. The prediction of breeding values by the mixed models is more adequate than the least squares method for average daily gain and for the index. The same does not occur with weight adjusted at 550 days. Selecting animals only by the phenotypic value may result in an incorrect ranking of the animals and animals with superior breeding values for average daily gain and index could be discarded.

\section{Acknowledgments}

The authors thank FAPEMIG and CNPq for the financial aid; Humberto de Freitas Tavares, for providing the data set; and Dr. Ignacy Misztal and collaborators, for providing free access to softwares REMLF90 and BLUPF90.

\section{References}

AGRAFNP. Anualpec 2011: anuário da pecuária brasileira. São Paulo: Agra FNP Pesquisas Ltda, 2011. 360p.

ASSOCIAÇÃO BRASILEIRA DE INSEMINAÇÃO ARTIFICIAL ASBIA. [2010]. Relatório estatístico de importação, exportação e comercialização de sêmen. Available at: <http://www.asbia. org.br/novo/upload/mercado/relatorio2010.pdf.> Accessed on: May 18, 2012.

AZEVÊDO, M.M.R.; MARTINS FILHO, R.; LÔBO, R.N.B. et al. Produtividade acumulada (PAC) das matrizes em rebanhos Nelore do norte e nordeste do Brasil. Revista Brasileira de Zootecnia, v.34, p.54-59, 2005.

BALDI, F.; ALBUQUERQUE, L.G.; CYRILLO, J.N.S.G. et al Genetic parameter estimates for live weight and daily live weight gain obtained for Nellore bulls in a test station using different models. Livestock Science, v.144, p.148-156, 2012. 
BEEF IMPROVEMENT FEDERATION - BIF. [2002]. Guidelines for Uniform Beef Improvement Programs. 9.ed. 2010. 183p. Available at: <http://www.beefimprovement.org/PDFs/guidelines/ 2010\%20Guidelines\%20,\%209th\%20Edition.pdf.> Accessed on: May 23, 2012.

BOLIGON, A.A.; SILVA, J.A.V; SESANA, R.C. et al. Estimation of genetic parameters for body weights, scrotal circumference, and testicular volume measured at different ages in Nellore cattle. Journal of Animal Science, v.88, p.1215-1219, 2010.

GONÇALVES, F.M; PIRES, A.V.; PEREIRA, I.G. et al. Avaliação genética para peso corporal em um rebanho Nelore. Arquivo Brasileiro de Medicina Veterinária e Zootecnia, v.63, p.158-164, 2011.

HENDERSON, C.R.; KEMPTHORNE, O.; SEARLE, S.R. et al. The estimation of environmental and genetic trends from records subject to culling. Biometrics, v.15, p.192-218, 1959.

PANETO, J.C.C.; LEMOS, D.C.; BEZERRA, L.A.F. et al. Estudo de características quantitativas de crescimento dos 120 aos 550 Dias de idade em gado Nelore. Revista Brasileira de Zootecnia, v.31, p.668-674, 2002.
PEREIRA, J.C.C. Melhoramento genético aplicado à produção animal. 5.ed. Belo Horizonte: Fundação de Estudo e Pesquisa em Medicina Veterinária e Zootecnia, 2008. 618p.

PEREIRA, M.A.; SOUZA, J.C.; MACHADO, C.H.C. Utilização de características produtivas para seleção de bovinos Nelore criados em Goiás. In: REUNIÃO ANUAL DA SOCIEDADE BRASILEIRA DE ZOOTECNIA, 46., 2009, Maringá. Anais... Maringá. Sociedade Brasileira de Zootecnia/Aptor, 2009. (CD-ROM).

RAZOOK, A.G.; FIGUEIREDO, L.A.; CYRILLO, J.N.S.G. et al. Prova de ganho de peso: normas adotadas pela Estação Experimental de Zootecnia de Sertãozinho. Nova Odessa: Instituto de Zootecnia, 1997. 42p. (Boletim Técnico, 40).

TOSH, J.J.; WILTON, J.W. Effects of data structure on variance of prediction error and accuracy of genetic evaluation. Journal of Animal Science, v.72 p.2568-2577, 1994.

YOKOO, M.J.; ALBUQUERQUE, L.G.; LOBO, R.B. et al. Estimativas de parâmetros genéticos para altura do posterior, peso e circunferência escrotal em bovinos da raça Nelore. Revista Brasileira de Zootecnia, v.36, p.1761-1768, 2007. 